\title{
Yenilenebilir Enerji Kaynaklarının Küresel İklim Değişikliği Üzerine Etkisi
}

\author{
Esra Deniz Güner ${ }^{1, *}$, Emine Su Turan² \\ ${ }^{1}$ Çukurova Üniversitesi, Mühendislik-Mimarlık Fakültesi, Çevre Mühendisliği Bölümü, 01330 Balcalı, Adana.

\section{Özet}

Sanayileşme sürecinin bir sonucu olarak 1870'li yıllardan bu yana, fosil yakıtların kullanımındaki artışla birlikte insanlık, küresel iklim değişikliği sorunuyla yüzleşmek zorunda kalmıştır. Bu sorun gelişmişlik düzeyinden bağımsız olarak dünya ülkelerinin hemen hepsini ciddi oranda etkilemektedir. Yenilenebilir enerji veya alternatif enerji kaynaklart son yıllarda savunulmakta olup, doğays koruma üzerine en fazla uzlaşı sağlamış önerme olarak öne çıkmaktadır. Küresel ısınma, iklim değişikliği ve sınırlı doğal kaynaklardaki azalmasıyla birlikte doğaya ve doğal kaynaklara zarar vermeyen enerji ve üretim biçimleri, bilhassa Kyoto Protokolünün imzalanmasını izleyen süreçte, devletlerin öncelikli taleplerinden biri haline gelmiştir. Bu çalışmada, küresel iklim değişikliği sorunu ve bu sorunun yönetimi için yenilenebilir enerji kaynakları kullanımının yaygınlaştırılmasının önemi ortaya konulmaktadır.

$\underline{\text { Anahtar Sözcükler }}$

Küresel İklim Değişikliği, Yenilenebilir Enerji, Sera Gazı, Fosil Yakıt, Kyoto Protokolü

\section{The Impact of Renewable Energy Sources on Global Climate Change}

\begin{abstract}
With the industrialization process, humanity has had to face the problem of global climate change through the intensive use of fossil fuels since the 1870s. This problem is seriously affecting all countries of the world regardless of the level of development. Renewable energy or alternative energy sources have been advocated in recent years, which is the most agreed proposition that has become prominent on the conservation of nature. With global warming, climate change, and scarcity of limited natural resources, the forms of energy and production that do not pollute nature have become one of the priority demands of the states especially since the signing of the Kyoto Protocol. In this study, the issue of global climate change and the importance of disseminating the use of renewable energy resources in respect to managing this problem were revealed.
\end{abstract}

$\underline{\text { Keywords }}$

Global Climate Change, Renewable Energy, Greenhouse Gas, Fossil Fuel, Kyoto Protocol

\section{Giriş}

İnsan yaşamının sürdürülebilmesi için en önemli gereksinim enerjidir. Ancak enerji temini politikalarında esas amaç çevresel tehdidi ortadan kaldırmak olmalıdır. Günümüzde gelişmişlik anlayışı, enerji bolluğu ve tüketimi yerine, enerjinin daha tasarruflu ve daha ekonomik olarak temin edebildiği teknoloji ve kaynak kullanımı anlayışı ile yer değiştirmiştir. Bu yeni bakış açısı "sağlıklı çevre", "enerji güvenliği” ve "enerji çeşitliliği” politikalarını beraberinde getirmiştir. Küresel ısınma ile iklim değişikliği etkilerinin azaltılması, bu yeni politikaların temelini oluşturmaktadır.

İklim değişikliği, çevre sorunları içerisinde en önemli problemlerden bir tanesi olmakla beraber, aynı zamanda diğer çevre kaynaklı sorunlar üzerinde de tetikleyici rol oynamaktadır. Bu durumun aksine iklim değişikliği, soğuk savaş dönemindeki yumuşama dönemlerinde çevre üzerine yapılan bazı girişimler ve konferanslar haricinde, 1980’li yıllara kadar uluslararası gündeme girememiş ve genel olarak yalnızca teknik çalışmaların ve bilimsel araştırmaların konusu olarak kalmıştır. Ancak bilimsel gelişmeler ve yaşanan doğal afetlerin sıklığının artması, konuyu uluslararası gündeme taşımış ve her geçen gün farkındalığın daha da arttığı bir hal almaya başlamıştır.

İklim değişikliği müzakereleriyle ilgili üç temel taş olduğu ifade edilmektedir. Bunlar; 1992 y1lında Rio de Janeiro'da düzenlenen Dünya Zirvesi'nde imzaya açılan ve 1994 yılında yürürlüğe girmiş olan Birleşmiş Milletler İklim Değişikliği Çerçeve Sözleşmesi, 1997 yılında imzaya açılan fakat ancak 2005 yılında yürürlüğe giren Kyoto Protokolü ve son olarak da iklim ile ilgili ilk defa küresel boyutta atılan bir adım olan 2015 Paris İklim Zirvesi (COP21)'dir. 
REC Türkiye (URL-1 2016), A’dan Z’ye İklim Değişikliği Başucu Rehberi’nde iklimi; “en basit ifadeyle, yeryüzünün herhangi bir yerinde uzun yıllar boyunca yaşanan ya da gözlenen tüm hava koşullarının ortalama durumu" ve daha sistematik bir yaklaşımla, "belirli bir alandaki hava koşullarının, atmosfer elemanlarının değişkenlikleri ve ortalama değerleri gibi uzun süreli istatistikleri ile tanımlanan sentezi (bileşimi)" olarak tanımlanmaktadır (Türkeş 1997; Türkeş 2000; Altunok ve Altunok 2016).

İklimdeki değişimin hızı ve büyüklüğü konusunda görüş birliğine varılamamıştır. Fakat Hükümetler arası İklim Değişikliği Panelinin (Intergovernmental Panel on Climate Change - IPCC) raporuna göre geçen yüzyılda (1906-2005) küresel ısınma miktarında $0.74 \pm 0.18^{\circ} \mathrm{C}$ 'lik bir değişimin olduğu kabul edilmektedir (IPCC 2016). İklim değişikliği, atmosfere salınan gazların neden olduğu düşünülen sera etkisinin sonucunda, dünya üzerinde yıl boyunca kara, deniz ve havada ölçülen ortalama sıcaklıklarda görülen artışı, başka bir deyişle küresel 1sınmayı da beraberinde getirmektedir (Sağsen 2016). Yapılan çalışmalar, iklim değişikliğinin insan sağlığına, tarım alanlarına ve ürünlere, su kaynaklarının miktar ve kalitesine, sahil bölgeleri ve doğal yaşam alanlarına doğrudan veya dolaylı olarak olumsuz etki edeceği konusunun altını çizmektedirler (Davis vd. 2007). Küresel ısınmanın sonucu iklim değişikliğinin engellenmesinde, fosil yakıt kullanımını azaltmak, yenilenebilir enerji kullanımı ve daha verimli üretim teknolojilerine öncelik verilmesi atılacak en önemli adımların başında gelmektedir.

Fosil yakıtların kullanımındaki artışla birlikte, gelişmişlik düzeyinden bağımsız olarak, dünya ülkelerinin hemen hepsi küresel iklim değişikliği sorunundan ciddi oranda etkilenmişlerdir. Bu çalışmada, küresel iklim değişikliği sorunu ve bu sorunun yönetimi için devletlerin öncelikli taleplerinden biri haline gelen, doğaya ve doğal kaynaklara zarar vermeyen yenilenebilir enerji kaynakları kullanımının yaygınlaştırılmasının ne denli önemli olduğunun ortaya konulması amaçlanmaktadır.

\section{Küresel İklim Değişikliği}

Küresel ısınma ile iklim değişikliğinin geri dönülmesi zor olan çarpıcı ekolojik ve çevresel zararlarının dünya gündemine girmesiyle, ulusal ve uluslararası önlemler alınmaya başlanmıştır. Bununla birlikte, ilk uluslararası adım olarak Birleşmiş Milletlerin 1972 y1lında düzenlediği konferans kabul edilebilir. Bu konferansta, iklim değişikliği ile ilgili oturumlar düzenlenmiş ve bu konunun dünya gündemine taşınması sağlanmıştır. Bu sürecin başlamaşndaki ilk adım, 1988 yılında Birleşmiş Milletler Çevre Programı ve Dünya Meteoroloji Örgütü’nün desteğiyle "Hükümetler arası İklim Değişikliği Panelinin (Intergovernmental Panel on Climate Change - IPCC)" kurulmasıdır (Mercan ve Karakaya 2013).

Sürdürülebilir enerji politikaları konusunda, küresel ısınma ve iklim değişikliğinin etkilerinin azaltılması için enerji yönetimi ve yenilenebilir enerji politikaları oluşturulması gerekliliği, alınacak başlıca önlemler arasında ilk sıralarda yer almaktadır (IPCC 2011).

Yenilenebilir enerji kaynaklarının kullanılmasıyla beraber küresel enerji kullanımından doğan karbon ayak izinin azaltılması mümkün olabilmektedir. 2030 yılına kadar yenilenebilir enerji payının iki katına çıkmasıyla emisyon salınımının yaklaşık yarısının azaltılması sağlanabilir ve enerji verimliliğiyle birleşince küresel sıcaklıktaki ortalama yükseliş $2^{\circ} \mathrm{C}$ 'nin altında $\left(1.5^{\circ} \mathrm{C}\right)$ tutulabilir ve iklim değişikliğinin küresel bir felaket olmasının önüne geçilebilir (Bayraç 2010; IPCC 2016; Doğan 2014).

Uluslararası Yenilenebilir Enerji Ajansı (IRENA)’nın yaptığı analizler, yenilenebilir enerji kaynakları ile ilgili yapılan yıllık toplam yatırımın 2030'a kadar 900 milyar \$ ulaşabileceğini göstermektedir (IEA 2015). Geleneksel yöntemlerle enerji kullanımı ve fosil yakıt kullanımına mahkum olunmasının önlenebilmesi için yıllık yatırımların 2020 yılına kadar günümüzdeki yatırım seviyelerinin neredeyse iki katına çıkarılması, 500 milyar \$ seviyelerine ulaşması gerekmektedir (IRENA 2015). İklim değişikliği yönetimi çalışmalarının başarılı olarak devam edebilmesi için yenilenebilir enerji dağılımı elektrikte artmaya devam etmeli, aynı zamanda ulaşım, 1sıtma ve soğutma faaliyetlerinde de yenilenebilir enerji kaynakları kullanımı arttırılmalıdır. Sürdürülebilir enerji geleceği için yapılması gerekenler IRENA tarafından beş başlıkta toplanmıştır (IRENA 2016). Bunlar;

- Yenilenebilir enerji politikasına bağlılığın güçlendirilmesi,

- Yenilenebilir enerji yatırımlarının harekete geçirilmesi,

- Yenilenebilir enerji kullanımının yayılmasını desteklemek için kurumsal ve teknik altyapının kurulması,

- Yenilenebilir enerji kullanımının sürdürülebilir kalkınmaya yararlarının ortaya konulması,

- Yenilenebilir enerji gelişiminde bölgesel katılım ve uluslararası işbirliğinin geliştirilmesidir.

\section{Türkiye'nin Sera Gazı Emisyonları}

Küresel ısınmanın esas nedeni, atmosferdeki sera gazlarının normal değerlerinden daha fazla olmasıdır. Sera gazlarının ana kaynağı sanayi faaliyetleri, dolayısıyla enerjidir. Enerji, karbon emisyonlarının temel belirleyicisi durumundadır ve üretim sürecini belirleyen ve devamlılığını sağlayan en önemli girdilerdendir. Çeşitli enerji türlerinin kullanılmasının farklı türlerde ve miktarlarda sera gazı salınımına neden olduğu bilinmektedir. Karbondioksit $\left(\mathrm{CO}_{2}\right)^{\prime}$ in dişında, metan $\left(\mathrm{CH}_{4}\right)$ ve diazot monoksit $\left(\mathrm{N}_{2} \mathrm{O}\right)$ enerji sektöründen yayılan güçlü sera gazlarıdır. $\mathrm{CO}_{2}$ ile kıyaslandığında $\mathrm{CH}_{4}$ 'nın küresel 1sınma potansiyeli 28-30 kat ve $\mathrm{N}_{2} \mathrm{O}$ 'nin küresel 1sınma potansiyeli 265 kat daha yüksektir (IRENA 2016). 
Enerji sektöründeki güçlü rekabetin önemli bir göstergesi olarak son 27 yılda salınan $\mathrm{CO}_{2}$ emisyon miktarı daha önceki yılarda salınan emisyon miktarına eşittir (Şekil 1). 1990 yılında IPCC ilk değerlendirme raporunun yayınlanmasından 2015 Paris iklim zirvesine kadar geçen 25 yılda küresel boyutta salınan sera gazı emisyon (Greenhouse gas - GHG) miktarlarında bir düşüş görülmemiştir (Şekil 1). Küresel ölçekte birincil enerji arzının \%80'den fazlasını fosil yakıtlar oluşturmaktadır. Enerji ile ilgili $\mathrm{CO}_{2}$ emisyonlarının \%90'ından fazlası fosil yakıtların kullanılmasından kaynaklanır (IRENA 2015). Fosil kaynaklı yakıt kullanımının, toplam sera gazı emisyonlarının enerji üretiminden kaynaklı paylarını azaltmak yerine arttırdığı gözlemlenmektedir (Şekil 1).

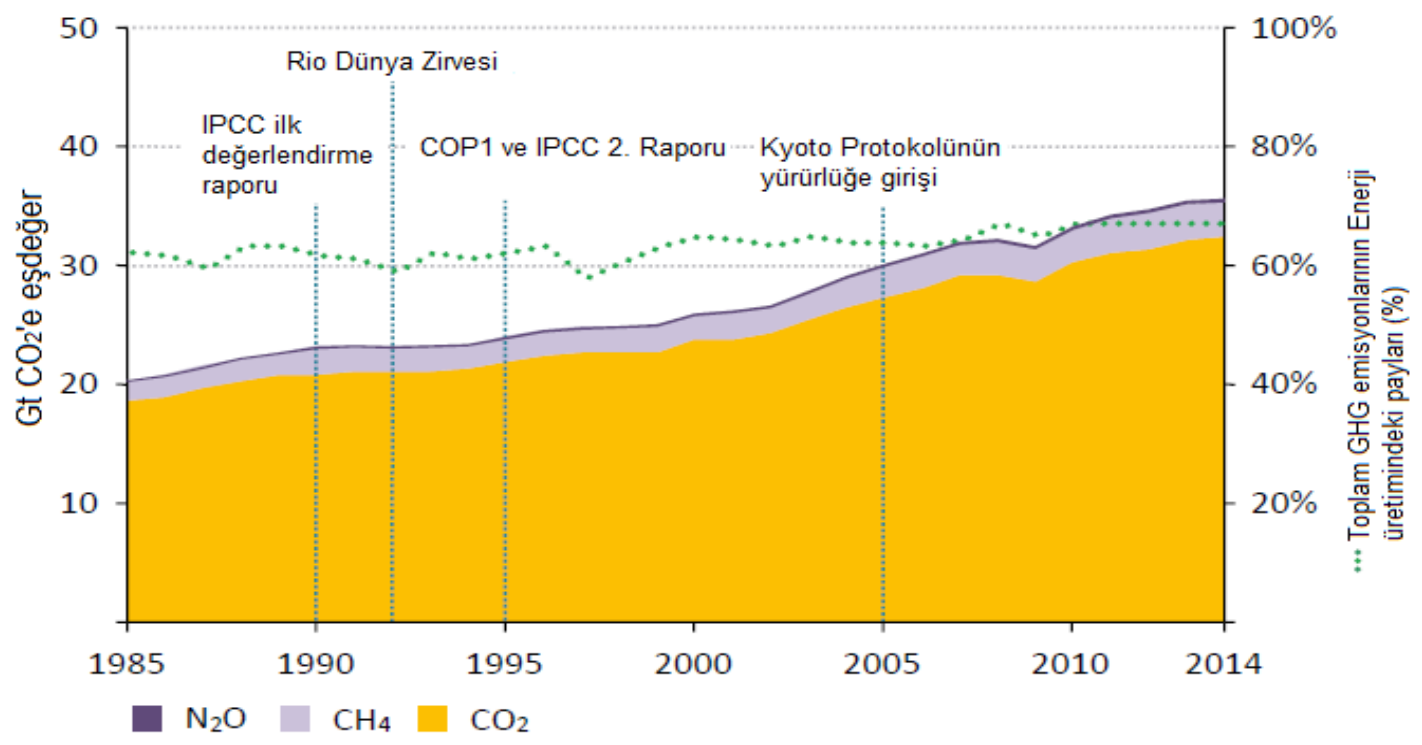

Şekil 1: Küresel Ölçekte Sera Gazı Emisyon Dağıımı (IEA 2015)

Enerji talebindeki artışın aksine sera gazı emisyonlarında \%60’lık bir azalma hedeflenmektedir (IPCC 2016). Az gelişmiş ülkelerin ekonomik büyüme ve gelişmelerini tamamlamaları, gelişmiş ülkelerin sera gazı emisyonlarını \%8090 gibi yüksek oranlarda azaltmalarına bağlıdır (IPCC 2016). Fakat bu hedef artan enerji arzı ile örtüşmemektedir (IEA 2007; Conti vd. 2011) .

İklim değişikliği çerçeve sözleşmesinde Türkiye OECD üyesi olduğu için EK-I üye ülke olarak sayılmıştır. Böylece sera gazı azaltımında birinci derece sorumlu ülke grubunda yer almıştır. Ancak herhangi bir sayısallaștırılmıș emisyon sınırlama veya azaltım yükümlülüğü bulunmamaktadır. COP21 zirvesinden sonra tüm katılımcı ülkelerin sera emisyonlarının azaltımında aktif yükümlülük alması kabul edilmiştir. Bu taahhüt ile her katılımcı ülkeden mevcut kapasitelerine göre azaltım yapılması istenmektedir. Ülkelerin beş yılda bir hedeflerini ve ilerleme durumlarını raporlamaları gerekmektedir. COP21 kapsamında Türkiye'nin sunduğu "Niyet Edilen Ulusal Katk1 Beyanında (INDC)" 2030 yılına kadar sera gazı emisyonlarının olağan seyir olan (Business as usual) referans senaryodan \%21 (246 Mt) daha az arttırılmasının hedeflendiği belirtilmiştir (IPCC 2016). Şekil 2'de görüldüğü gibi hiçbir önlem alınmaksızın olağan seyirde devam edilmesi halinde 2030 yılında 1 milyar 175 ton $\mathrm{CO}_{2}$ 'e sera gazı salınımı olacağı anlaşılmaktadır.

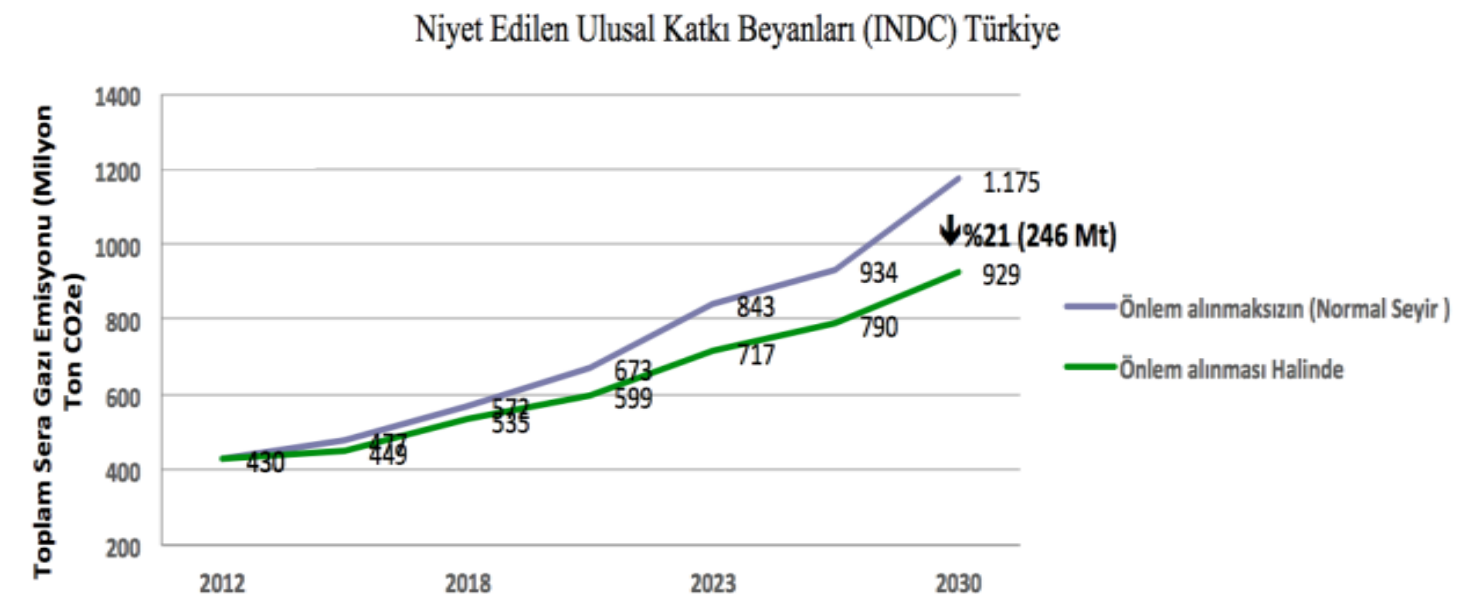

Şekil 2: INDC Belgesi'nde Türkiye'nin Toplam Sera Gazı Emisyon Taahhüdü (URL-2 2016) 
Önlem alınması durumunda bu miktarın 929 milyar ton $\mathrm{CO}_{2}$ 'e kadar düşürülebileceği INDC'de taahhüt edilmiştir. Bu Türkiye'nin herhangi bir ekonomik destek almadan kendi çabasıyla yapabileceği azaltımı ifade etmektedir. 2014 yılında, Türkiye'nin toplam sera gazı emisyonunun $\mathrm{CO}_{2}$ eşdeğeri olarak 467.6 milyon ton olduğu TÜİK Sera Gazı Envanterinde belirtilmiştir (TÜİK 2016). $\mathrm{CO}_{2}$ eşdeğeri olarak 2014 yılı toplam sera gazı emisyonu, 1990 y1lına göre \%125 artış göstermiştir (Şekil 3). Şekil 3'de görüldüğü üzere en fazla sera gazı salınımı enerji sektöründe gerçekleşmektedir. 2014 yılı emisyonlarında $\mathrm{CO}_{2}$ eşdeğeri olarak en yüksek oran \%72.5 ile enerji kaynaklı emisyonlardan kaynaklanmaktadır. Bunun ardından, endüstriyel işlemler ve ürün kullanımı \%13.4, tarımsal faaliyetler \%10.6, atık \%3.5'lik paya sahiptir (TÜIK 2016).

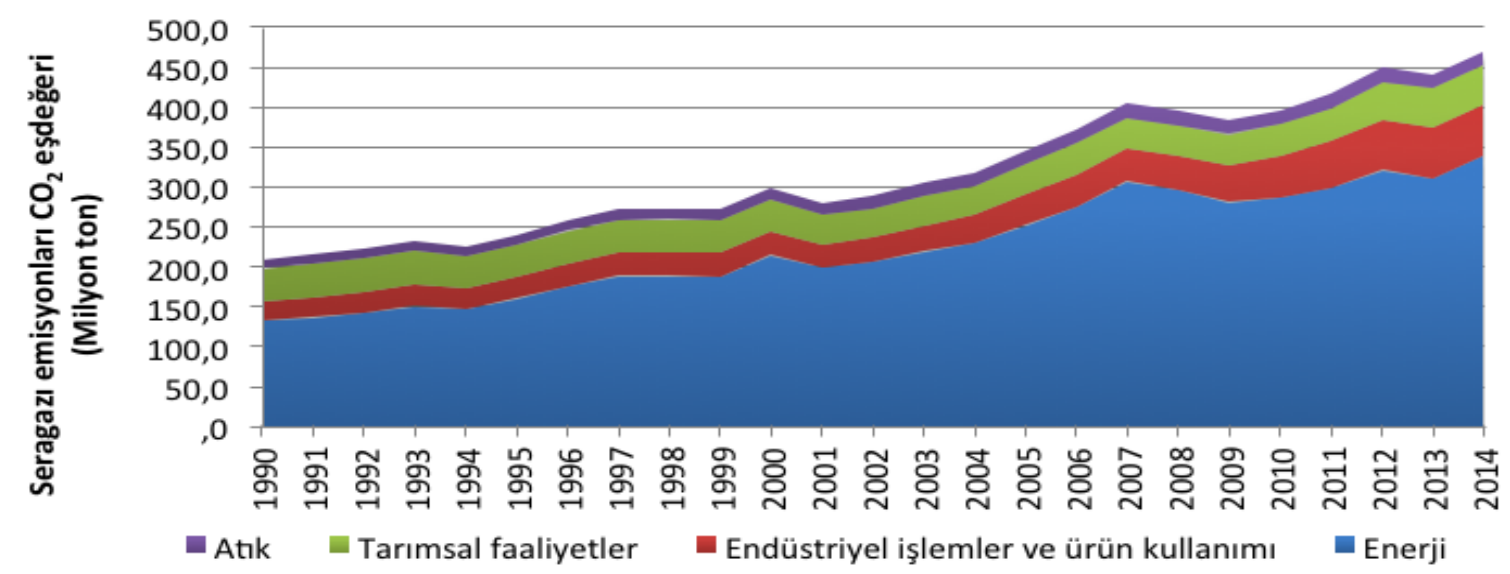

Şekil 3: Türkiye Seragazı Emisyonları CO2 Eşdeğeri (milyon ton) (TÜík 2016)

\section{Yenilenebilir Enerji Politikaları}

Biyokütle (odun, hayvan), hidrolik, jeotermal, güneş, rüzgar, denizlerde gel-git ve dalgalardan elde edilen enerji yenilenebilir, nükleer, petrol, kömür ve doğal gazdan elde edilen enerji ise yenilenemeyen enerji kaynaklarıdır. Yenilenemeyen enerji kaynakları birincil enerji kaynağı olarak değerlendirilmektedir. Yenilenemeyen enerji kaynaklarından meydana gelen üretim (elektrik, petrol ürünleri) ise ikincil enerji kaynaklarıdır.

Düşük karbon ekonomisi politikaları ile küresel boyutta yenilenebilir enerji kaynaklarının kullanımı her geçen gün payını arttırmaktadır. Uluslararası Enerji Ajansı (IEA) ülkelerinde bu payın arttırılması için uygulanan teşvikler ile yenilenebilir enerji kaynaklarının payı 1970-2002 yılları arasında 2 kat artarak yılda \%5.7'ye ulaşmıştır. Bu payın 2030 yılına kadar \%60 seviyelerine ulaşması beklenmektedir (IEA 2015). Dünya elektrik üretiminin yenilenebilir enerji kaynaklardan sağlanması giderek yaygınlaşmaktadır. Geçen on yılda dünya ölçeğinde yenilenebilir enerji kaynaklarının kullanımı ile elektrik üretimin payı \%7.4'lük artış göstermiştir. ABD, Almanya, İspanya, Brezilya ve Japonya gibi gelişmiş ülkeler bu payın \%52'sini oluşturmaktadır (IPCC 2016). Elbette diğer kaynaklar ile kıyaslandığında yenilenebilir enerji teknolojileri halen ekonomik açıdan istenilen maliyet düzeylerinde değildir. Ancak, yenilenebilir enerji kaynaklı enerji üretim teknolojilerindeki gelişmelerin maliyetleri düşüreceği açıktır. Uzun vadede etkin maliyet değerlerine ulaşılacağı ve 2030 yılına kadar düşen birim maliyetler ile elektrik üretiminde yenilenebilir enerji kaynaklarının kullanım payının 3 kat artacağı ön görülmektedir (Conti vd. 2011). AB Yenilenebilir Enerji Mevzuatı ile beraber ekosistem üzerindeki olumsuz etkilerin azaltılması ve taahhüt edilen iklim değişimi hedeflerini karşılamak için 2003/30/EC direktifinde yenilenebilir yakıt kullanımında oran ve gösterge hedeflerini belirlemek zorundadır. Bu hedefler kapsamında 2020 yılına kadar tüm enerjisinin \%20’si yenilenebilir kaynaklardan elde edilmesi planlanmıștır (GWEC 2012).

$\mathrm{Bu}$ politika doğrultusunda elektrik üretim sektörlerine göre daha yavaş ilerleseler bile AB Enerji komisyonu özellikle taşımacılık sektöründe ki ilerleyişi arttırmak yönündedir. Düşük karbon ekonomisi, daha uygun fiyatlı "temiz" enerjiye dayalı, fosil yakıtlara bağımlılığını kırmak için ulaşım sektöründe bioyakıtların (biobenzin, biodizel, biogaz), üretim ve tüketiminin teşvik edilmesini istemektedir.

Refah ve kalkınma hedeflerine paralel olarak Türkiye, iklim değişikliğine sebep olan fosil yakıtlara bağımlılığını azaltmak için yüksek yenilenebilir enerji potansiyelinin kullanımına yönelik Ar-Ge çalışmalarını ve teknolojilerini geliştirmektedir. Bu doğrultuda erimiş karbonatlı yakıt pilleri, yakıt hazırlama- hidrojen üretimi, güneş enerjisi ısıtma sistemleri, fotovoltaik piller, yanma ve gazlaştırma sistemleri, elektrikli ve hibrit araç teknolojileri, enerji depolama ve yönetim sistemleri, alternatif yakıtlı araçlar, yanma ve proses gazlardan çeşitli artıkların temizlenmesi gibi teknolojik uygulamalar yapılmaktadır (Doğan 2005; Doğan 2014).

Ekonomik gelişme ve nüfus artışı nedeniyle, toplam birincil enerji arzı sürekli yükselen bir eğilim göstermektedir. Genel olarak toplam enerji talebindeki artış, 1990 yılında 52.9 milyon TEP iken 2014 yılında 123.94 milyon TEP olarak gerçekleşmiştir (URL-3 2016). 
Enerji kullanımı ekonomik büyümenin, gelişmişliğin bir yansıması olduğu düşünüldüğünde Türkiye artan eğilime sahip olduğu görülmektedir. Ancak Türkiye, birincil enerji (yenilenemeyen) kaynakları bakımından sınırlı olup dışa bağımlı bir ülkedir. Petrol (\%90) ve doğal gaz (\%95) açısından dışa bağımlılık oldukça yüksektir (IEA 2007; URL-3 2016; IRENA 2016). Kömür açısından zengin bir ülke sayılsak ta bu rezervlerimizin çoğu linyit kömürüdür. Linyit ısıl değeri düşük olması, Kükürt oksitler $\left(\mathrm{SO}_{\mathrm{x}}\right)$, azot oksitler $\left(\mathrm{NO}_{\mathrm{x}}\right)$ sebebi ile çevresel kirliliğe, sera etkisine ve dolayısıyla küresel ısınmaya yol açmaktadır.

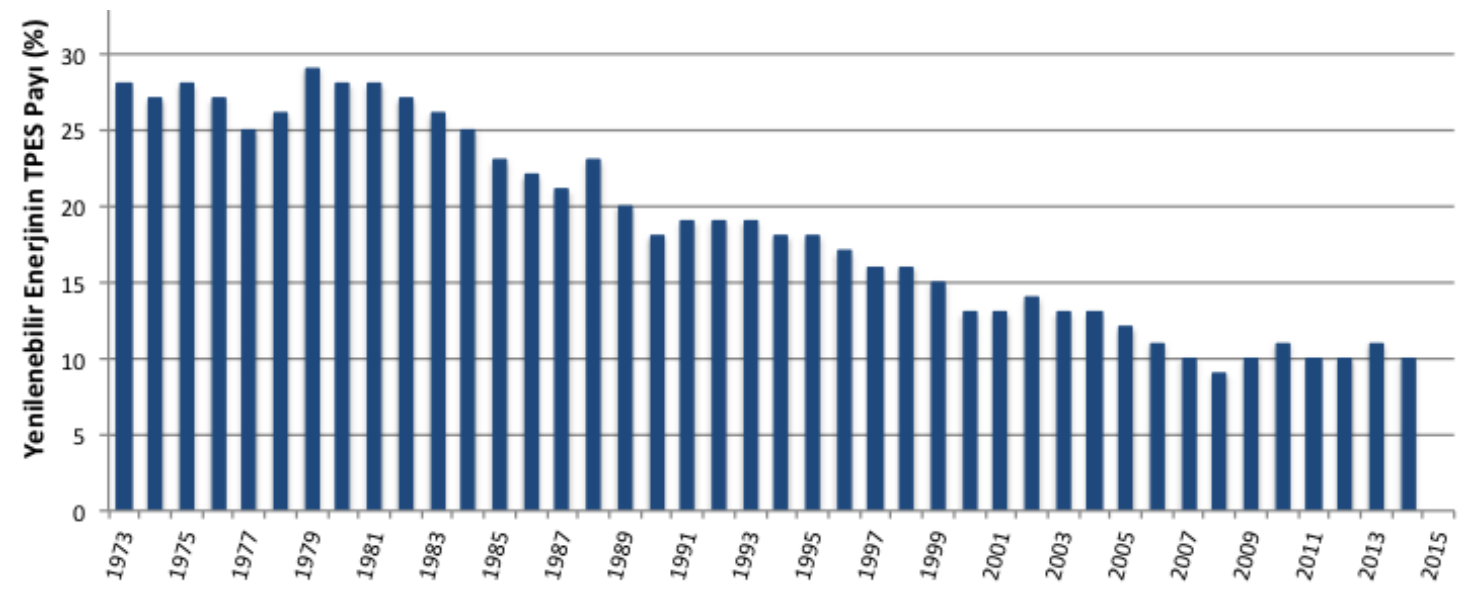

Şekil 4: Türkiye'deki yenilenebilir enerjinin birincil enerji arzındaki payı (\%) (TÜIKK 2016)

(TPES: Total primary energy supply - Toplam Birincil Enerji Arzı)

Son yıllardaki enerjide talep artışına rağmen, yenilenebilir enerjinin toplam birincil enerji arzındaki payının neredeyse sabit olduğu görülmektedir (Şekil 4). Özellikle elektrik üretimindeki net artışın aksine yenilenebilir enerji payının çok az arttı̆̆ görülmektedir (Şekil 5).

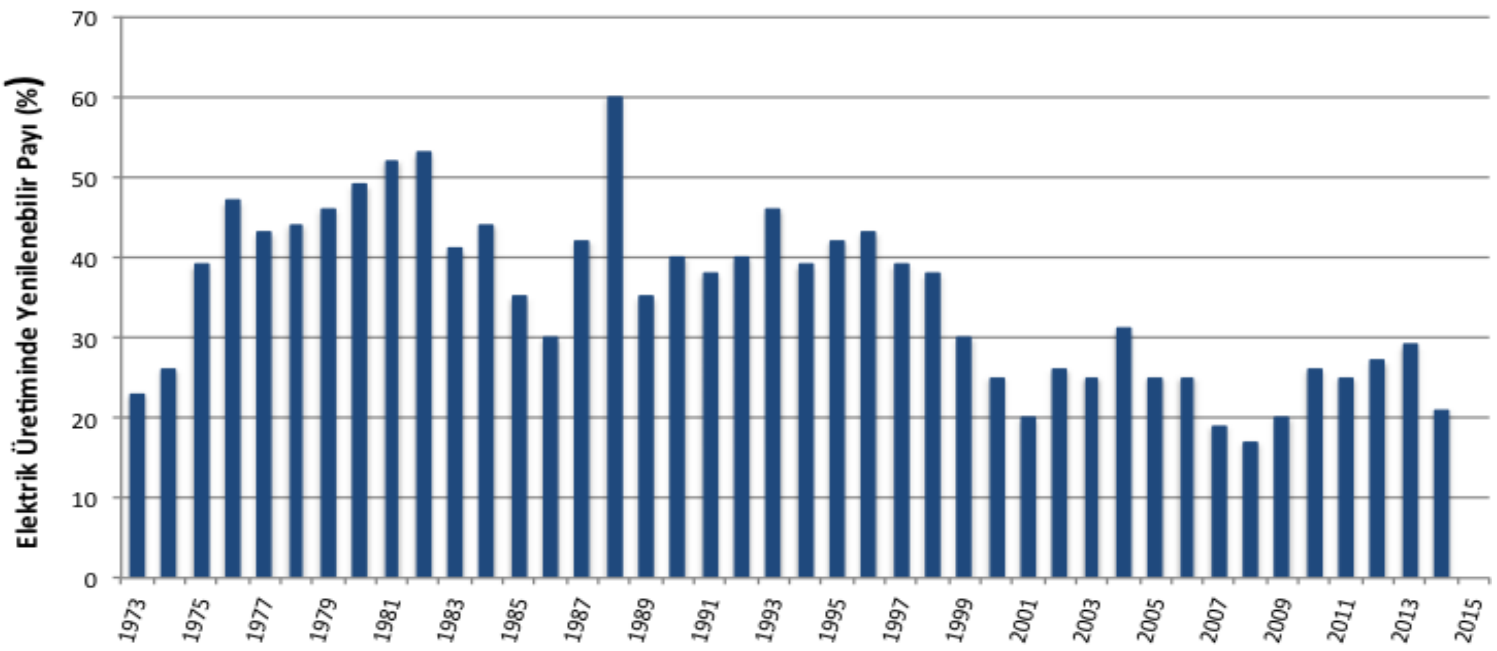

Şekil 5: Türkiye'deki elektrik üretiminde yenilenebilir payı (\%) (TÜÍK 2016)

Ülkemizde fosil yakıtlar enerji talebine hakim durumdadır. 2014 yılında 122 Mtoe (petrol eşdeğeri enerji) arzı sağlanmıştır. 2014 verilerine göre enerji arzında \%33.2 (40.1 Milyon TEP) ile doğalgaz birinci sıradayken, bunu \%29.6 ile kömür (35.8 Milyon TEP), \%27.1 (32.7 Milyon TEP) ile petrol takip etmiştir. Geri kalan \%10.1'lik bölüm ise hidrolik \%2.9 (3.4 Milyon TEP) olmak üzere jeotermal, güneş ve rüzgar \%4.3 (5.1 Milyon TEP) ve bioyakıt ve atıklar \% 2.9 (3.5 Milyon TEP) olarak yenilenebilir kaynaklardan karşılanmıştır (Şekil 6) (IRENA 2016).

Birincil enerji talebimizin 2023 yılına kadar \% 90 oranında artarak 218 milyon TEP'e ulaşması tahmin edilmektedir. Bu kümülatif içinde \% 37'si kömür, \% 23’ü doğal gaz, \% 26's1 petrol olmak üzere hidrolik enerjinin ve nükleer enerjinin \% 4 ile yenilenebilir ve diğer enerji kaynaklarının payının \% 6'lık paya sahip olması beklenmektedir (URL-3 2016).

Artan nüfus, sanayileşme ve enerji üretiminde yenilenebilir enerji kaynaklarının oldukça düşük seviyelerde olması ve enerji talebinin birincil kaynaklardan sağlanması büyüme ve enerji üretimi arasında ilişkinin kurulamamasına yol açmaktadır. 


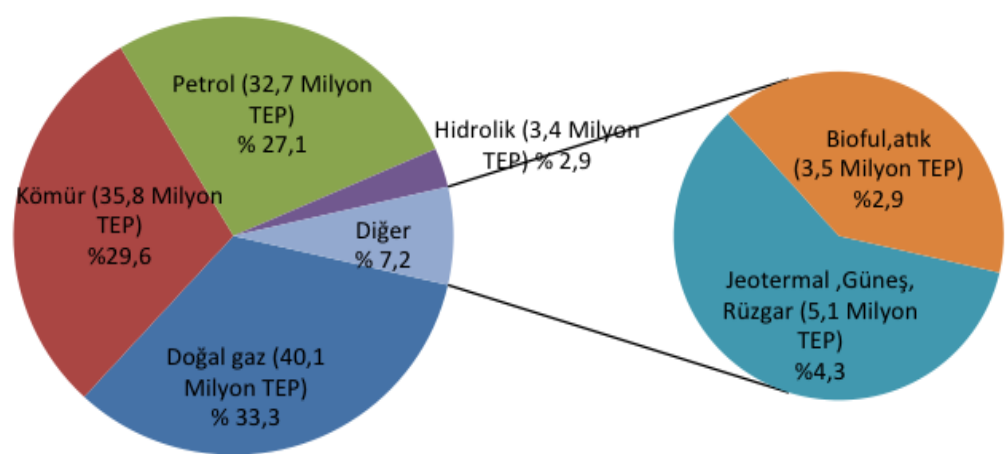

Şekil 6: Türkiye'deki 2014 yılı birincil enerji arzının kaynak dağılımı (Tüík 2016)

2014 yılı itibari ile Türkiye'deki toplam enerji üretiminde yenilenebilir enerjinin payı \% 37'lerde kalmaktadır (Şekil 7). Türkiye'nin yenilenebilir enerjinin kullanımı ile dışa bağımlılık oranının azaltılabileceği düşünülmektedir. Ayrıca COP21'de bulunduğu ulusal taahhüdü yerine getirebilmesi için yenilenebilir enerjiye dair hedeflerini daha yüksek tutmasının gerekliliği açıktır.

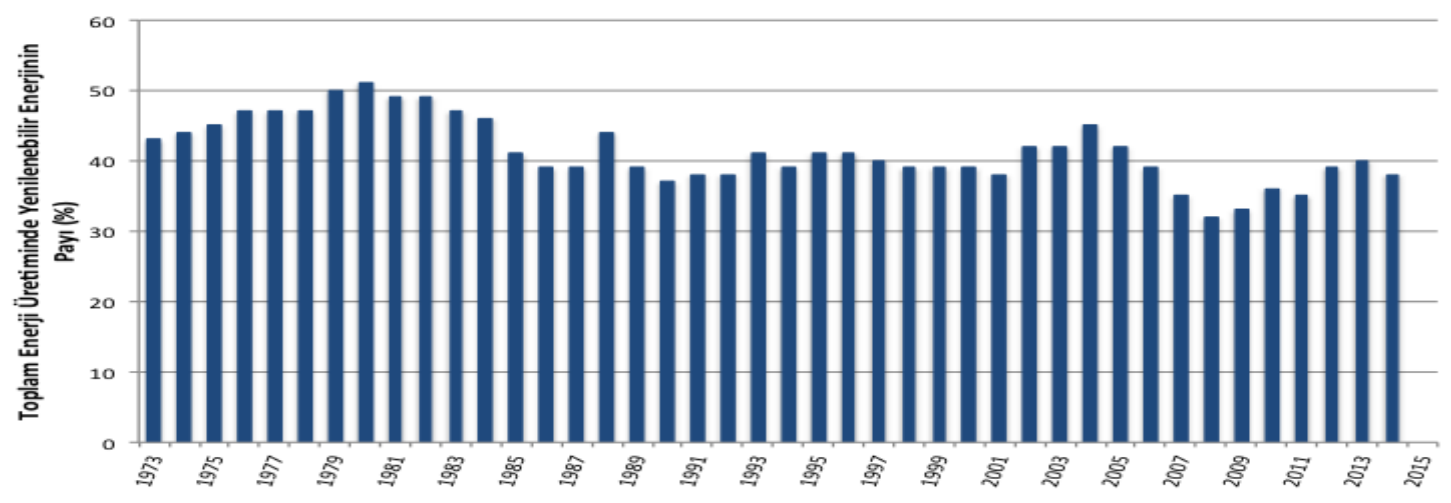

Şekil 7: Türkiye'deki toplam enerji üretiminde yenilenebilir enerjinin payı (\%) (TÜIKK 2016)

Ulusal İklim Değişikliği Stratejisi kapsamında referans senaryoya göre enerji piyasasında2020 yılına kadar \%7 karbondioksit emisyon sınırlaması ve 2023 yılının sonunda yenilenebilir enerjinin toplam elektrik enerjisi üretimindeki payının yüzde 30'a ulaşması amaçlanmıştır. 2013 yılı itibari ile 428.3 MW rüzgar, 2.114 MW hidrolik, 148.6 MW jeotermal ve $65.5 \mathrm{MW}$ çöp gazı, biokütle ve atık 1s1, $310 \mathrm{MW}$ jeotermal elektrik üretim santrallerinin kurulu gücü mevcuttur. Ayrıca 2030 yılına kadar hidrolik potansiyellin tamamı değerlendirilirken, rüzgarda $16 \mathrm{GW}$ ve jeotermalde 600 MW elektrik üretim kapasitesine ulaşması hedeflenmiştir (URL-3 2016). Güneş enerjisinden elektrik enerjisi elde edilmesi özendirilecektir. 2030 yılına kadar güneş enerjisinden $10 \mathrm{GW}$ ’lık elektrik üretimine ulaşması sağlanacaktır.

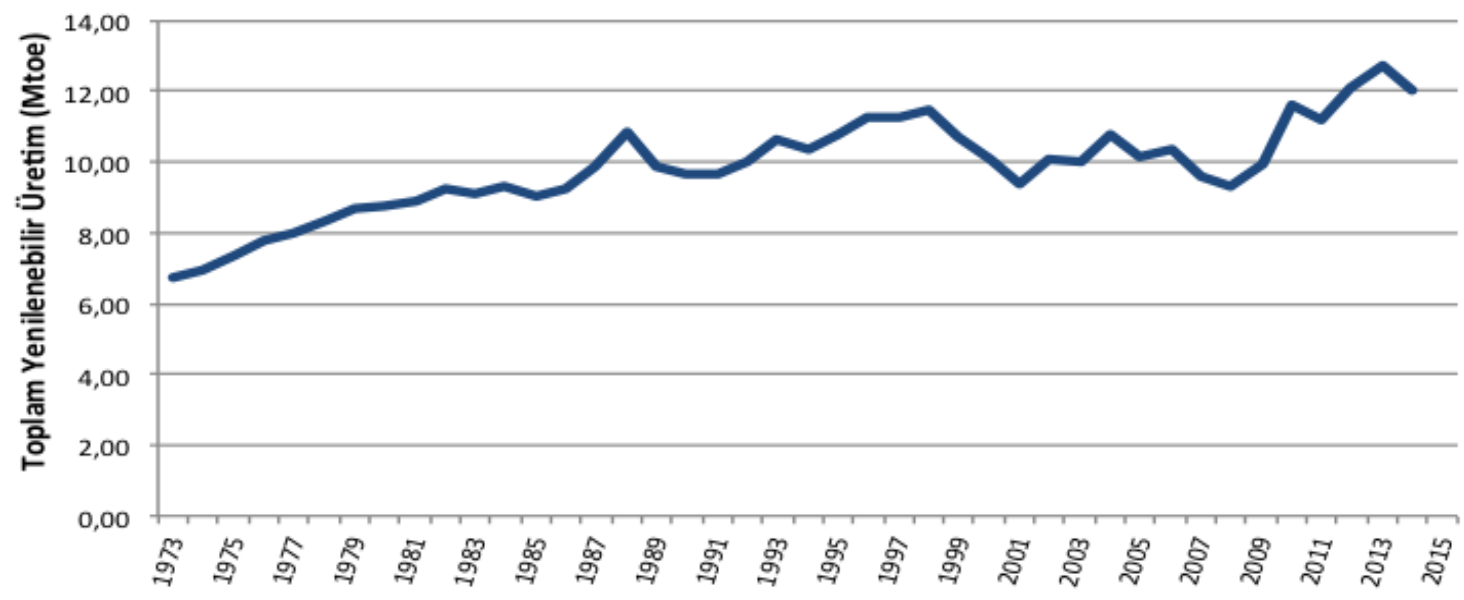

Şekil 8: Türkiye'de Toplam Yenilenebilir Üretim (Mtoe) (TÜIK 2016) 
1994, 1999, 2001 ve 2009 ekonomik krizler yıllarında toplam yenilenebilir enerjiden üretimin düştüğü görülmektedir (Şekil 8). Bu tesis alanlarının maliyet yüksekliği, uygulama alanlarının az ve özellikle küçük işletmelerle sınırlı kalmasından kaynaklanabilir. Ancak son y1llarda toplam yenilenebilir kaynaklardan enerji üretiminin arttı̆̆ ve 12 Mtoe’a ulaştığı görülmektedir (Şekil 8).Ülkemizin sahip olduğu yenilenebilir enerji talebinin karşılanmasındaki rolünü arttırmak; dışa bağımlılığı azaltırken, çevresel duyarlılığı artırarak iklim değişikliğine katkı azaltılabilir. İklim değişikliğinden ve neden olduğu olumsuz etkilerinden kaçınmak için yürütülen çalışmaların Ulusal İklim Değişikliği Stratejisi kapsamında yürütülmesi, sürdürülebilir kullanımın sağlanması, yenilenebilir enerji kaynakların etkili bir şekilde yönetilmesine olanak verecektir.

\section{Sonuç}

Nüfus artışı, sanayileşme ve enerji talebinde artışa, bunlar da kaynak kullanımındaki artışa sebep olur. Böylece daha fazla fosil yakıt kullanımı ile bir zincirleme döngüyü oluşturmaktadır. Bu döngü beraberinde iklim değişikliğine neden olan karbondioksit ve diğer sera gazlarını beraberinde getirmektedir. Dünyayı tehdit eden en büyük çevre sorunlarından biri sera gazı artışı ile küresel ısınmadır. Türkiye, küresel ısınmanın yıkıcı sonuçları bakımından, riskli ülkeler arasında bulunmaktadır. Uzun vadede sürdürülebilir ekonomiyi desteklemek ve çevresel etkileri azaltmak için yenilenebilir enerji kaynaklarının kullanımı kilit rol oynayacaktır. Ancak burada devletin büyük bir potansiyele sahip olan yenilenebilir enerji kaynaklarını sürekli destekleyen ve teşvik eden finansal bir politika izlemesi gereklidir.

Yenilenebilir enerji kullanımı, enerji şirketlerinin hedef ve yatırımlarında yenilenebilir enerji ağırlıklı bir yol izlemeleri şartını koyarak ya da mali yardımlar yaparak teşvik edilebilir. Alım garantisi ile süre, miktar ve fiyatlandırmada yüksek politikalar izlenerek yatırımcıların önünü açmalıdır. Böylece ilk yatırım masrafı ve kullanılan yüksek teknolojinin sağlayacağı ekonomik dezavantaj ortadan kaldırılabilir. Ekonomik rekabet gücü arttırılan yenilenebilir enerji politikası ile geri dönülmesi mümkün olmayan küresel 1sınmanın yaratacağı ekolojik zararlar azaltılabilir. Enerjinin daha etkin ve idareli kullanımı ile enerji verimliliği desteklenerek karbon emisyonlarını azaltmak da bir diğer önemli adımdır. Yenilenebilir enerji kaynaklarının enerji arzının sağlanmasındaki katkısının yükseltilmesi; çevreye duyarlı, sürdürülebilir ve dışa bağımlılığın azaltılmasına yüksek katkı sağlayacaktır. Enerji temininde kaynak çeşitliliği (güneş, rüzgar, jeotermal gibi) ithalattan kaynaklanan risklerin azaltılmasında da önemlidir. İklim ve enerji politikalarının beraber oluşturulması daha kalıcı çözümler üretilmesi açısından oldukça önemlidir. İklim değişikliğiyle mücadele için düşük karbonlu yatırım politikaları ile Bakanlık kalkınma politikalarının uyumlu hale getirilmesinin oldukça önemli olduğu dikkate alınmalıdır.

\section{Kaynaklar}

Altunok A. E., Altunok E., (2016), AB İklim Değişikliği Politikaları, Denetişim, 12(12), 45-55.

Bayraç H.N., (2010), Enerji kullanımının küresel ısınmaya etkisi ve önleyici politikalar, Eskişehir Osmangazi Üniversitesi Sosyal Bilimler Dergisi, 11(2), 229-260.

Conti J.J., Holtberg P.D., Beamon J.A., Schaal A., Ayoub J., Turnure J.T., (2011), Annual energy outlook 2011 with projections to 2035, United States of America Department of Energy Information, Office of Integrated and International Energy Analysis, http://www.eia.gov/neic/speeches/newell_12162010.pdf, [Erişim 16 Kasım 2016].

Davis C.P., Aladdine D.J, Carrie F.J., (2007), Climate Change Strategies for the Financial Services Industry, Goodwin Procter LLP.

Dogan N., (2014), The role of renewable energy resources in fighting against global climate change: An assessment for Turkey, IIB International Refereed Academic Social Sciences Journal, 5(15), 265-276.

Doğan S., (2005), Türkiye'nin küresel iklim değişikliğinde rolü ve önleyici çabaya katılım yaklaşımları, Cumhuriyet Üniversitesi İktisadi ve İdari Bilimler Dergisi, 6(2), 57-73.

GWEC, (2012), Global wind report: Annual market update 2011, Global Wind Energy Council, Brussels, Belgium, http://gwec.net/wp-content/uploads/2012/06/Annual_report_2011_lowres.pdf, [Erişim 01 Aral1k 2016].

IEA, (2007), World Energy Outlook, International Energy Agency, France, https://www.iea.org/publications/freepublications/ publication/weo_2007.pdf, [Erişim 28 Aralık 2016].

IEA, (2015), Energy Climate and Change, World Energy Outlook Special Report, International Energy Agency, France, https://www.iea.org/publications/freepublications/publication/WEO2015SpecialReportonEnergyandClimateChange.pdf, [Erişim 27 Kasim 2016].

IPCC, (2011), Renewable energy sources and climate change mitigation, Summary for policy makers and technical summary, https://www.ipcc.ch/pdf/special-reports/srren/SRREN_FD_SPM_final.pdf, [Erișim 20 Aralık 2016].

IPCC, (2016), Renewable energy sources and climate change mitigation, Special report of the intergovernmental panel on climate change, https://www.ipcc.ch/pdf/special-reports/srren/SRREN_FD_SPM_final.pdf, [Erişim 20 Aralık 2016].

IRENA, (2015), Rethinking Energy: Renewable Energy and Climate Change, International Renewable Energy Agency, https://www.irena.org/rethinking/IRENA\%20_REthinking_Energy_2nd_report_2015.pdf, [Erişim 26 Kasım 2016].

IRENA, (2016), Renewable Capacity Statistics 2016, International Renewable Energy Agency, http://www.irena.org/Document Downloads/Publications/IRENA_RE_Capacity_Statistics_2016.pdf, [Erişim 26 Aralık 2016].

Mercan M., Karakaya E., (2013), Sera gazı salımının azaltımında alternatif politikaların ekonomik maliyetlerinin incelenmesi: Türkiye için genel denge analizi, Erciyes Üniversitesi, İktisadi ve İdari Bilimler Fakültesi Dergisi, 2013 (42), 123-159.

Sağsen, İ., (2016), Dünyanın geleceği üzerine önemli bir viraj: 2015 İklim Değişikliği Zirvesi, Ortadoğu Analiz, 8(72), $72-75$. 
TÜIK, (2016), TEİAŞ, Türkiye Elektrik Üretim - Illetim İstatistikleri, http://www.tuik.gov.tr/PreTablo.do?alt_id=1029, [Erişim 20 Aralık 2016].

Türkeş M., (1997), Hava ve iklim kavramları üzerine, TÜBİTAK Bilim ve Teknik Dergisi, 355, 36-37.

Türkeş M., (2000), Hava, İklim, Şiddetli Hava Olayları ve Küresel Isınma, TC Başbakanlık Devlet Meteoroloji İşleri Genel Müdürlüğ̈̆, 187-205.

URL-1, (2016), A’dan Z'ye İklim Değişikliği Başucu Rehberi, Bölgesel Çevre Merkezi REC Türkiye, https://recturkey.files. wordpress.com/2016/11/adanzye_iklim_degisikligi_basucurehberi.pdf, [Erişim 22 Aralık 2016].

URL-2, (2016), Republic of Turkey Intended Nationally Determined Contribution, http://www4.unfccc.int/submissions/INDC/ Published\%20Documents/Turkey/1/The_INDC_of_TURKEY_v.15.19.30.pdf, [Erişim 26 Aralık 2016].

URL-3, (2016), 2014 Yll Bütçe Sunumu, T.C Enerji ve Tabii Kaynaklar Bakanlığı, Strateji Geliştirme Başkanlığı, 13 Aralık 2013, http://www.enerji.gov.tr/File/?path=ROOT\%2F1\%2FDocuments\%2FSayfalar\%2F2014+Y\%C4\%B11\%C4\%B1+B\%C3\%BCt\%C 3\%A7esinin+TBMM+Genel+Kuruluna+Sunumu.pdf, [Erişim 27 Kasım 2016]. 